\title{
Modeling of Camembert-Type Cheese Mass Loss in a Ripening Chamber: Main Biological and Physical Phenomena
}

\author{
A. Hélias, ${ }^{* 1}$ P.-S. Mirade, $†$ and G. Corrieu* \\ *UMR782 Génie et Microbiologie des Procédés Alimentaires, Institut National de la Recherche Agronomique (INRA), AgroParisTech, \\ F-78850 Thiverval-Grignon, France \\ †UR370 Qualité des Produits Animaux, Institut National de la Recherche Agronomique, Theix, F-63122 St Genès Champelle, France
}

\section{ABSTRACT}

A model of the mass loss of Camembert-type cheese was established with data obtained from 2 experimental ripening trials carried out in 2 pilot ripening chambers. During these experiments, a cheese was continuously weighed and the relative humidity, temperature, oxygen, and carbon dioxide concentrations in the ripening chamber were recorded online. The aim was to establish a simple but accurate model that would predict cheese mass changes according to available online measurements. The main hypotheses were that 1) the cheese water activity was constant during ripening, 2) the respiratory activity of the microflora played a major role by inducing heat production, combined with important water evaporation, 3 ) the temperature gradient existing inside the cheese was negligible, and the limiting phenomenon was the convective transfer. The water activity and the specific heat of the cheeses were assessed by offline measurements. The others parameters in the model were obtained from the literature. This dynamic model was built with 2 state variables: the cheese mass and the surface temperature of the cheese. In this way, only the heat transfer coefficient had to be fitted, and it was strongly determined by the airflow characteristics close to the cheeses. Model efficiency was illustrated by comparing the estimated and measured mass and the mass loss rate for the 2 studied runs; the relative errors were less than 1.9 and $3.2 \%$ for the mass loss and the mass loss rate, respectively. The dynamic effects of special events, such as room defrosting or changes in chamber relative humidity, were well described by the model, especially in terms of kinetics (mass loss rates).

Key words: dynamic modeling, respiration heat, mass loss, cheese ripening

Received April 11, 2007.

Accepted June 27, 2007.

${ }^{1}$ Corresponding author: arnaud.helias@grignon.inra.fr

\section{INTRODUCTION}

Ripening is one of most important steps in the cheesemaking processes. It is characterized by the development of a microbial consortium whose activities are responsible for important biological and physicochemical changes that occur on the surface and at the core of the curd as a function of ripening time (Choisy et al., 2000). All biological activities are influenced by the atmosphere of the ripening chamber, especially its temperature, relative humidity, and gas composition (Ramet, 2000, Picque et al., 2006). In parallel with these transformations that occur on and in the curd, gas exchanges attributable to water evaporation and carbon dioxide emission have been noted. Ramet (2000) estimated a cheese mass loss of 3 to $8 \%$ at the ripening room level according to the cheese type. From an industrial point of view, the mass loss has consequences on productivity, especially for protected designation of origin (PDO) products, for which the weight is a conformity criterion (e.g., Camembert-Normandie PDO and Epoisses PDO require a final weight of $0.25 \mathrm{~kg}$ ).

Mass transfer from the curd to the surrounding atmosphere depends on several factors. Weissenfluh and $\mathrm{Pu}$ han (1987), Macedo et al. (1997), and Simal et al. (2001) studied the effect of relative humidity. Weissenfluh and Puhan (1987) and Mirade et al. (2004) described the consequences of airflow rate. A more detailed analysis of these works was done by Picque et al. (2006). Variations in the gas composition of the ripening chamber were studied by Mirade et al. (2006). Because of its consequences on the biological activity of microbial consortia and on ripened cheese quality, the chamber temperature is also considered as an important variable. Riahi et al. (2007) established a model for predicting the weight and DM of a smear soft cheese during the ripening. The model of Riahi et al. (2007) 1) was based on lactose and lactate measurements and 2) included a relation between water activity $\left(a_{w}\right)$ and water content.

Heat and mass transfer are commonly studied in cooking and drying processes, but little data have been published about their role in cheese ripening. Two speci- 
ficities characterize cheese ripening as compared with the cooking and drying processes: 1) the temperature variations are very small and the atmospheric relative humidity is close to saturation; 2) biological transformations cannot be neglected in comparison with physical and chemical changes. Hence, the use of a cheeselike product without the biological aspects (as was done by Mirade et al., 2004) is not sufficient, even if it allows a good comprehension of heat transfer and mass transfer.

Cheese ripening can be considered as solid substrate fermentation (SSF). Raimbault (1998) summarized several aspects of SSF. This author emphasized that biomass measurements are very difficult and that their direct evaluation is nearly impossible. In some cases, microbial growth can be estimated by respiratory metabolism (oxygen consumption and carbon dioxide release measurements). Second, he noted that heat transfer is probably the most crucial factor in large-scale $\mathrm{SSF}$ processes. Substrate oxidation catabolism is highly exothermic, and the main element for heat loss is evaporation.

Saucedo-Castañeda et al. (1990) developed a model for SSF heat transfer simulation in a bioreactor. It focuses on convective phenomena with a spatial representation of temperature, and takes into account the microbial growth through a logistic model. Nagel et al. (2001) built a model of moisture content control during SSF. In their work, water evaporation was measured directly and the release of carbon dioxide and consumption of oxygen allowed the changes in DM loss and water content to be determined (metabolic water production, substrate hydrolysis, and water incorporated into new biomass). However, no thermal aspect was treated. Mitchell et al. (2003) reviewed several heat and mass transfer models in bioreactors for SSF. Spatial representation was used in these different works; each model was dedicated to a specific type of bioreactor.

The aim of this paper was to model the dynamics of cheese mass loss resulting from physical and biological phenomena. Variables describing the ripening chamber atmosphere were considered as inputs of the model. After describing ripening conditions and available measurements, we describe the model and associated hypotheses. A simple model was built with some constants selected from the literature and, in a few cases, with constants established from experimental measurements. Afterward, the model was fitted and validated on 2 experimental ripening trials.

\section{MATERIALS AND METHODS}

\section{Cheese Making and Ripening Chambers}

Two runs were performed in 2 small ripening chambers of $0.91 \mathrm{~m}^{3}(1.9 \times 0.8 \times 0.6 \mathrm{~m})$ for trial 1 and 0.63 $\mathrm{m}^{3}(1.2 \times 0.6 \times 0.87 \mathrm{~m})$ for trial 2 . In both cases, Camembert-type cheeses were manufactured (one batch for each run) by using the protocol previously described by Leclercq-Perlat et al. (2004). To complement the lactic acid bacteria inoculate, a ripening microbial consortia composed by Kluyveromyces marcianus, Geotrichum candidum, Penicillium camemberti, and Brevibacterium aurantiacium was used. After drainage, the molded cheeses were transferred into the ripening chambers and placed into a refrigerated room to allow temperature control close to $14 \pm 1^{\circ} \mathrm{C}$.

\section{Data Acquisition}

For each run, a cheese was continuously weighed on an electronic balance (Precisa XB620C, precision \pm 0.01 g, Precisa, Poissy, France). A combined sensor (Vaissala, HMP 243 Dewpoint transmitter, Etoile International, Paris, France) measured the chamber temperature and the relative humidity of the ripening chamber. It was located $6 \mathrm{~cm}$ above the weighed cheese, a distance greater than the thermal boundary layer according to Harris et al. (2004). To determine the cheese and chamber temperatures, the average of thermocouple measurements (K type, Correge Temperature, Pacy-surEure, France) were carried out. Three thermocouples were placed $0.01 \mathrm{~m}$ under the surface of a cheese (experimental constraints did not allow us to weigh and measure the temperature of the same cheese) and 3 others ones were placed $6 \mathrm{~cm}$ above. The thermocouples were calibrated before the trial in a water bath (temperatures: 10 and $15^{\circ} \mathrm{C}$ ) and the calibration was checked after ripening in the same way. Chamber atmospheric composition changes were also characterized by $\mathrm{CO}_{2}$ (Iridium 100 infrared analyzer, City Technology, UK) and $\mathrm{O}_{2}$ (CiTycel electrochemical sensor, City Technology) sensors.

When the ripening chamber was used without an input of air, the variations in $\mathrm{CO}_{2}$ and $\mathrm{O}_{2}$ concentrations depended only on the exchanges between the atmosphere and the cheeses. To study cheese respiration activity, cubic smoothing spline functions (MatLab, The Mathworks, Natick, MA) were used to derive the gas concentration as a function of time, and then the $\mathrm{CO}_{2}$ production and $\mathrm{O}_{2}$ consumption rates were obtained. All online data (mass, temperature, relative humidity, $\mathrm{O}_{2}$ and $\mathrm{CO}_{2}$ concentrations) were carried out on a computer within a 6 -min acquisition period.

Water activity $\left(\boldsymbol{a}_{\boldsymbol{w}}\right)$ and specific heat were assessed in cheeses from run 1 . We considered that the values were representative of cheeses in both chambers because the variability in $a_{w}$ is very low in soft cheeses (see below) and specific heat depends mainly on the water content and fat matter, 2 cheese characteristics 
that do not vary in a large range for a given cheese type. The $a_{w}$ at the cheese surface was measured daily on each face of 2 cheeses by using a nondestructive method (FA-st lab, GBX, Romans sur Isère, France). A differential scanning calorimeter (Pyris 1, PerkinElmer LLC, Norwalk, CT) equipped with a liquid nitrogen cooling accessory (CryoFill, PerkinElmer) was used to measure specific heat on 3 different cheeses on d 1, 7, and 14.

\section{Run Description}

For trial 1, 45 cheeses were placed on 2 parallel trays, and for run 2, 22 cheeses were placed on 2 parallel trays. The cheese radius and thickness were 5.5 and $3.5 \mathrm{~cm}$, respectively. The initial mass of the weighted cheese was $330 \mathrm{~g}$ for run 1 and $340 \mathrm{~g}$ for run 2 . For run 1 , the defrosting cycle of the refrigerated room had an 8 -h period. It induced an increase of $1^{\circ} \mathrm{C}$ during the first hour of the cycle and a relative humidity variation of $2 \%$. The relative humidity was manually controlled for run 1 (through 2 cold traps placed inside the chamber) and automatically controlled for run 2 (air was treated with a cold trap placed outside the chamber, with a fan to manage the airflow rate in this recirculation loop). According to Camembert-making technology, the first ripening day had a low relative humidity value (close to 85\%) to allow surface drying of the curd. The following 13 days of run 1 were carried out with controlled variations of relative humidity (between 88 and $94 \%$ ) to study the effect of relative humidity on mass loss. For run 2, the set point for the following 13 days was a relative humidity of $92 \%$. To study the effect of air velocity on heat and mass transfer, the fan was on between $\mathrm{d} 1$ and 7 , and it was off for the rest of the time. In all conditions, the air velocities were lower than $0.1 \mathrm{~m} \cdot \mathrm{s}^{-1}$. To avoid too high a $\mathrm{CO}_{2}$ concentration in the ripening chamber, which could induce cheese faults (Picque et al., 2006), manual gas renewal was performed periodically, with a roughly 1 -d period for run 1 , when the $\mathrm{CO}_{2}$ concentration was higher than $2 \%$, and a roughly 0.5 -d period for run 2 , when the $\mathrm{CO}_{2}$ concentration was higher than $1 \%$.

\section{Modeling}

Mass Loss. The cheese mass loss is the result of water evaporation (a physical phenomenon) and of carbon dioxide release (a biological phenomenon). The evaporative flux of water is a function of the difference in the water vapor pressure between the ripening chamber and the cheese surface. Cheese surface $a_{w}$ is a key parameter for this transfer. On food products, the link between $a_{w}$ and water content is generally represented by the sorption isotherm. Several empirical or semiempirical models have been set up. The Guggenheim, Anderson, De Boer equation is probably the most frequently used in the food industry (Chirife and Iglesias, 1978). Water activity mainly results from the ionic composition and water content. Another important effect for dairy products is the micelle structure, which depends on the $\mathrm{pH}$ (Rüegg and Blanc, 1976). Saurel et al. (2004) reviewed several studies on $a_{w}$ modeling for cheese with various complexities and emphasized the difficulty of establishing general relationships.

In this work, 2 points were taken into account. First, the $a_{w}$ values of soft cheese are very high, up to 0.95 (Hardy, 2000). Taking into account the sorption curve, important water content variations imply only small changes in $a_{w}$ for values close to 1 . According to the experimental water sorption isotherm shown by Desobry and Hardy (1994), a water content variation of 0.6 to $0.4 \mathrm{~g}_{\text {water }} / \mathrm{g}_{\mathrm{DM}}(37.5$ to $28.6 \%)$ implies $a_{w}$ changes of 0.97 to 0.95 . The high water content (50 to $60 \%$ ) of the experimental cheeses allowed us to suppose a very small influence on $a_{w}$. Consequently, the relation between $a_{w}$ and water content of the cheese is not necessary for mass loss estimation. Second, according to Hardy (1985), after $3 \mathrm{~d}$ of ripening, salt concentrations are similar at the core and in the rind of a Camembert. The small size of Camembert and its important water content could explain this rapid equilibrium. Consequently, brining influences the cheese $a_{w}$ value, but no significant variation of this factor occurs during ripening. Considering these aspects, the $a_{w}$ was taken as constant and no water or salt diffusion phenomena inside the cheese were represented.

Biological activities are characterized by oxygen consumption and carbon dioxide production, which induce gas exchanges between the cheeses and the ripening chamber atmosphere. Other gaseous productions (such as ammonia and aroma compounds) are considered to be negligible from a mass dynamic point of view. Anaerobic pathways at the core level cannot be neglected for cheese taste elaboration, but they are not significantly involved in mass loss. For Camembert-type cheeses, the main part of the biological activity and gaseous exchange in the ripening process is localized at the rind level (Blanc et al., 1983). Aerobic pathways prevail when the respiration quotient (RQ) is near 1 , which is the case for Camembert-type cheeses (Picque et al., 2006). The $\mathrm{O}_{2}$ consumption rate $\left(r_{\mathrm{O}_{2}}\right)$ and the $\mathrm{CO}_{2}$ production rate $\left(r_{\mathrm{CO}_{2}} ; \mathrm{mol} \cdot \mathrm{m}^{-2} \cdot \mathrm{s}^{-1}\right)$ were calculated from $\mathrm{CO}_{2}$ and $\mathrm{O}_{2}$ concentrations measured in the ripening chamber. The matter balance linked to respiration was obtained by the difference between these 2 rates.

For a given cheese, the rate of cheese mass $[m(\mathrm{~kg})]$ variation is represented as follows $\left(\mathrm{kg} \cdot \mathrm{d}^{-1}\right)$ : 
Table 1. Constants used to mass loss estimation

\begin{tabular}{|c|c|c|c|}
\hline Parameter & Symbol & Value $\left(\mathrm{SEM}^{1}\right)$ & Source \\
\hline $\mathrm{O}_{2}$ molar mass $\left(\mathrm{kg} \cdot \mathrm{mol}^{-1}\right)$ & & $3.2 \times 10^{-2}$ & \\
\hline $\mathrm{CO}_{2}$ molar mass $\left(\mathrm{kg} \cdot \mathrm{mol}^{-1}\right)$ & $w_{\mathrm{CO}_{3}}$ & $4.4 \times 10^{-2}$ & \\
\hline Respiration heat $\left(\mathrm{J} \cdot \mathrm{mol}^{-1}\right)$ & & $4.693 \times 10^{5}$ & Kang and Lee, 1998 \\
\hline Latent heat of water evaporation ${ }^{2}\left(\mathrm{~J} \cdot \mathrm{kg}^{-1}\right)$ & $\lambda$ & $2.47 \times 10^{6}$ & Perry and Green, 1997 \\
\hline Product emissivity (dimensionless) & $\varepsilon$ & 0.91 & Mirade et al., 2004 \\
\hline Stefan-Boltzmann constant $\left(\mathrm{W} \cdot \mathrm{m}^{-2} \cdot \mathrm{K}^{-4}\right)$ & $\sigma$ & $5.67 \times 10^{-8}$ & Perry and Green, 1997 \\
\hline Surface area of cheese ${ }^{3}\left(\mathrm{~m}^{2}\right)$ & $s$ & $2.6 \times 10^{-2}$ & Experimental determination \\
\hline Surface water activity (dimensionless) & $a_{w}$ & $0.976(0.001)$ & Experimental determination \\
\hline Specific heat $\left(\mathrm{J} \cdot \mathrm{kg}^{-1} \cdot \mathrm{K}^{-1}\right)$ & $C$ & $2.194 \times 10^{3}(59)$ & Experimental determination \\
\hline
\end{tabular}

${ }^{1}$ SEM used for experimental acquisitions.

${ }^{2}$ Latent heat of water evaporation value calculated at $14^{\circ} \mathrm{C}$.

${ }^{3}$ Total surface of the cheese $\left(3.11 \times 10^{-2} \mathrm{~m}^{2}\right)$ less the surface covered by the grid $\left(0.51 \times 10^{-2} \mathrm{~m}^{2}\right)$ where the cheese was placed during the ripening.

$$
\begin{gathered}
\frac{d m}{d t}=s\left\{w_{\mathrm{O}_{2}} \cdot r_{\mathrm{O}_{2}}-w_{\mathrm{CO}_{2}} \cdot r_{\mathrm{CO}_{2}}-k\left[a_{w} \cdot p_{s v}\left(T_{s}\right)\right.\right. \\
\left.\left.-r h \cdot p_{s v}\left(T_{\infty}\right)\right]\right\}
\end{gathered}
$$

where $s\left(\mathrm{~m}^{2}\right)$ is the useful surface exchange of the cheese (see Table 1), calculated from the product dimensions minus the surface of the grid support (corresponding to $46 \%$ of the inferior side). The molar masses $\left(\mathrm{kg} \cdot \mathrm{mol}^{-}\right.$

${ }^{1}$ ) of oxygen and carbon dioxide are $w_{\mathrm{O}_{2}}$ and $w_{\mathrm{CO}_{2}}$, respectively. The cheese surface water activity is $a_{w}$. The average cheese surface and ripening chamber temperatures are $T_{s}$ and $T_{\infty}$, respectively (K). The relative humidity is $r h$ (expressed between 0 and 1 ). The saturation vapor pressure is $p_{s v}\left(T_{*}\right)$ at temperature $T_{*}$ (i.e., $T_{s}$ or $T_{\infty} ; \mathrm{Pa}$ ), it was calculated from the temperature with the GoffGratch equation (World Meteorological Organization, $2000) . k$ is the average water transfer coefficient $\left(\mathrm{kg} \cdot \mathrm{m}^{-}\right.$ $\left.{ }^{2} \cdot \mathrm{Pa}^{-1} \cdot \mathrm{s}^{-1}\right) ; k$ was assumed to be constant for a given airflow pattern around the cheese (this point is explained later).

Cheese Surface Temperature. According to Hardy and Scher (2000), the conductivity of cheese heat varies between 0.3 to $0.4 \mathrm{~W} \cdot \mathrm{m}^{-1} \cdot \mathrm{K}^{-1}$. The cheese Biot number is thus between 0.24 and 0.32 . Consequently, the heat conduction inside the product is very fast. There is no thermal gradient inside the cheese, and the cheese surface temperature is assumed to be representative of the cheese temperature.

Direct heat exchange between the cheeses and their close atmosphere results from convective and radiant fluxes; in addition to these phenomena, the moisture loss induces an evaporative heat consumption flux. The cheese rind presents a high biological activity during ripening, characterized by the important development of a mycelium. From an energetic point of view, fermentative pathways can be neglected, as described by $\mathrm{Pa}-$ jonk et al. (2003) for Emmental ripening heat transfer. In contrast, respiratory heat must be taken into ac- count. For the storage of several vegetable food products (Kang and Lee, 1998; Song et al., 2002), the generic glucose aerobic respiration equation is used:

$$
\begin{gathered}
\mathrm{C}_{6} \mathrm{H}_{12} \mathrm{O}_{6}+6 \mathrm{O}_{2} \rightarrow 6 \mathrm{CO}_{2}+6 \mathrm{H}_{2} \mathrm{O} \\
+2.816 \times 10^{6} \mathrm{~J} \cdot \mathrm{mol}^{-1} .
\end{gathered}
$$

Equation [2] gives an RQ equal to 1 because of the equimolarity between $\mathrm{O}_{2}$ and $\mathrm{CO}_{2}$. In the cheese context, many substrates are oxidized (lactose, lactate, and partially lipids and proteins), which can induce an RQ variation close to 1 . The variability of $R Q$ was thus represented by the average of $r_{\mathrm{O}_{2}}$ and $r_{\mathrm{CO}_{2}}$.

From these considerations, the rate of cheese surface temperature variation is represented as follows:

$$
\begin{gathered}
\frac{d T_{s}}{d t}=\frac{s}{m \cdot C}\left\{h\left(T_{\infty}-T_{s}\right)+\varepsilon \sigma\left(T_{\infty}^{4}-T_{s}^{4}\right)\right. \\
\left.-\lambda k\left[a_{w} \cdot p_{s v}\left(T_{s}\right)-r h \cdot p_{s v}\left(\mathrm{~T}_{\infty}\right)\right]+\alpha \frac{r_{\mathrm{O}_{2}}+r_{\mathrm{CO}_{2}}}{2}\right\},
\end{gathered}
$$

where $C$ is the cheese-specific heat $\left(\mathrm{J} \cdot \mathrm{kg}^{-1} \cdot \mathrm{K}^{-1}\right) ; h$ is the average convective heat transfer coefficient $\left(\mathrm{W} \cdot \mathrm{m}^{-2} \cdot \mathrm{K}^{-}\right.$ $\left.{ }^{1}\right) ; \varepsilon$ is the cheese emissivity (dimensionless); $\sigma$ is the Stefan-Boltzmann constant $\left(\mathrm{W} \cdot \mathrm{m}^{-2} \cdot \mathrm{K}^{-4}\right) ; \alpha$ is the respiration heat for $1 \mathrm{~mol}$ of carbon dioxide release $\left(\mathrm{J} \cdot \mathrm{mol}^{-}\right.$ ${ }^{1}$ ); and $\lambda$ is the latent vaporization heat of water $\left(\mathrm{J} \cdot \mathrm{kg}^{-}\right.$ $\left.{ }^{1}\right)$. The average value depends on the ripening temperature, but it can be taken with an error smaller than $0.2 \%$ because of the low temperature change (10 to $15^{\circ} \mathrm{C}$ ) during ripening.

Transfer Coefficients. The effect of the small variations in temperature (less than $5^{\circ} \mathrm{C}$ ) and relative humidity (less than 10\%) on the average convective heat and mass transfer coefficients, $h$ and $k$, respectively, can be neglected. Consequently, $h$ and $k$ are mainly determined by the shape of the cheese and the airflow 


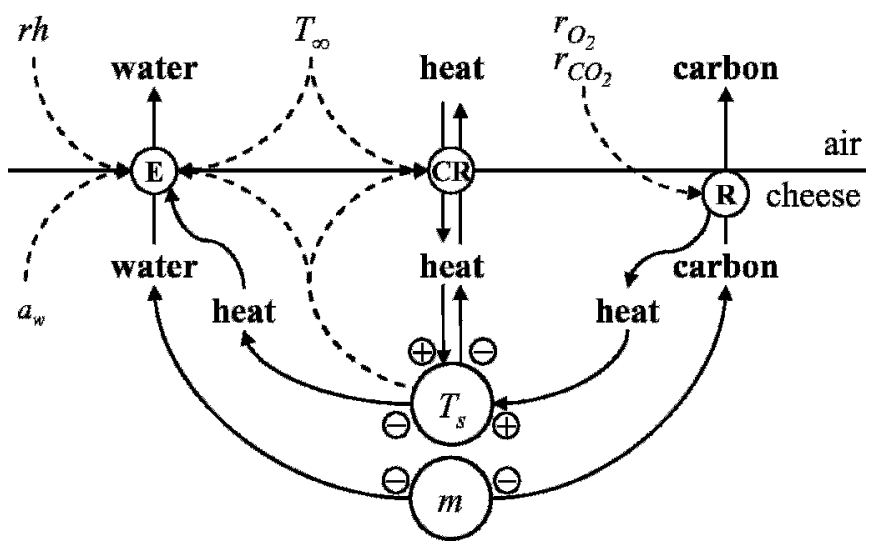

Figure 1. Schematic representation of the model. Input variables: relative humidity $(r h)$, atmospheric temperature $\left(T_{\infty}\right)$, oxygen consumption rate $\left(r_{\mathrm{O}_{2}}\right)$, and carbon dioxide production rate $\left(r_{\mathrm{CO}_{2}}\right)$. Constant: water activity $\left(a_{w}\right)$. State variables: surface temperature $\left(T_{s}\right)$, mass $(m)$. Phenomena: water evaporation $(\mathrm{E})$, convective and radiant exchanges $(\mathrm{CR})$, respiratory activity $(\mathrm{R})$. A dashed arrow represents a variable influence on a phenomenon; a solid arrow shows the consequences (positive or negative) of a phenomenon on a state variable.

properties (Kondjoyan and Daudin, 1997). Mirade et al. (2004) used the psychrometric method to determine the transfer coefficient values of a Camembert-shaped plaster object according to the average airflow, $v\left(\mathrm{~m} \cdot \mathrm{s}^{-1}\right)$ :

$$
\begin{gathered}
h=3.95 e^{2.23 v}\left(\mathrm{~W} \cdot \mathrm{m}^{-2} \cdot \mathrm{K}^{-1}\right), \text { and } \\
k=2.92 e^{2.42 v} \cdot 10^{-8}\left(\mathrm{~kg} \cdot \mathrm{m}^{-2} \cdot \mathrm{Pa}^{-1} \cdot \mathrm{s}^{-1}\right) .
\end{gathered}
$$

Unfortunately, these relations were not relevant for the very low air velocity measured in the studied ripening chambers $\left(v\right.$ was lower than $0.1 \mathrm{~m} \cdot \mathrm{s}^{-1}$; data not shown). Indeed, Ozisik (1985) established the theoretical $h$ value $\left(1.9 \mathrm{~W} \cdot \mathrm{m}^{-2} \cdot \mathrm{K}^{-1}\right)$ for a nonstirred chamber, which is different from the result (3.95) obtained with equation [4].

Because of the high sensitivity of mass loss with respect to transfer coefficients, $h$ was obtained by a nonlinear least-squares regression with the LevenbergMarquardt method (Marquardt, 1963) between estimated and measured mass for the different airflow conditions. In this case, the following relation was established from equations [4] and [5]:

$$
k=0.66 \cdot 10^{-8} \cdot h^{1.09}\left(\mathrm{~kg} \cdot \mathrm{m}^{-2} \cdot \mathrm{Pa}^{-1} \cdot \mathrm{s}^{-1}\right) .
$$

Model Overview. Figure 1 gives an overview of the model composed of equations [1] and [3]. With 4 input variables $\left(r h, T_{\infty}, r_{\mathrm{O}_{2}}\right.$, and $\left.r_{\mathrm{CO}_{2}}\right)$ and 2 state variables $\left(T_{s}\right.$ and $m$ ), the 3 main phenomena taken into account were 1) the water evaporation, which induced a decrease in mass and energy consumption; 2 ) the convective and radiant heat fluxes, governed by the difference between the cheese surface and the chamber temperatures; and 3) the exothermic respiratory metabolism, which induced carbon loss.

This model differs from the model established by Riahi et al. (2007), which considered lactose and lactate concentrations (obtained from offline analysis) as data input. In the present study, the oxygen and carbon dioxide concentration measurements were used. Moreover, heat production linked to respiratory activity was taken into account, and the $a_{w}$ of the cheese was considered as a constant.

\section{RESULTS AND DISCUSSION}

\section{Run Description}

Figure 2 (A to $\mathrm{F}$ ) represents the online data acquisition performed for the 2 runs and used as input for the model. For run 1 (Figure 2, left panels), the chamber temperature was between 286 and $289 \mathrm{~K}$, as a function of a defrosting event performed automatically every $8 \mathrm{~h}$. This phenomenon also induced relative humidity variations, decreases for low relative humidity values and increases for high values. The dry air injections carried out to remove the $\mathrm{CO}_{2}$ produced important decreases in relative humidity (e.g., $d 7$ to 11 in Figure $2 \mathrm{~A})$. In addition to these abrupt changes, manual low relative humidity variations, between 88 and 94\%, were carried out to study changes in the mass loss kinetics.

Run 2 (Figure 2, right panels) was carried out in a ripening chamber with an automated relative humidity control and without defrosting events. From d 0 to $d 1$ and from $d 7$ to the end of the run, the fan of the recirculation loop was stopped, and the regulation of relative humidity was carried out by natural convection. This implied 2 different airflows close to the cheeses (fan off and fan on).

Figure $2 \mathrm{G}$ and $2 \mathrm{H}$ represents the oxygen consumption rate and the carbon dioxide production rate for the 2 runs. These were established from data shown in Figure $2 \mathrm{E}$ and $2 \mathrm{~F}$, respectively: gas rates were the first derivative of the gas concentrations according to time. During the air injection time, the calculations were not done and interpolated values were used.

\section{Verification of the Model Hypotheses}

Water Activity. The experimental measurements of $a_{w}$ carried out on the surfaces of the cheeses during run 1 are shown on Figure 3. The water loss throughout the ripening process did not appear to influence $a_{w}$. 
Run 1
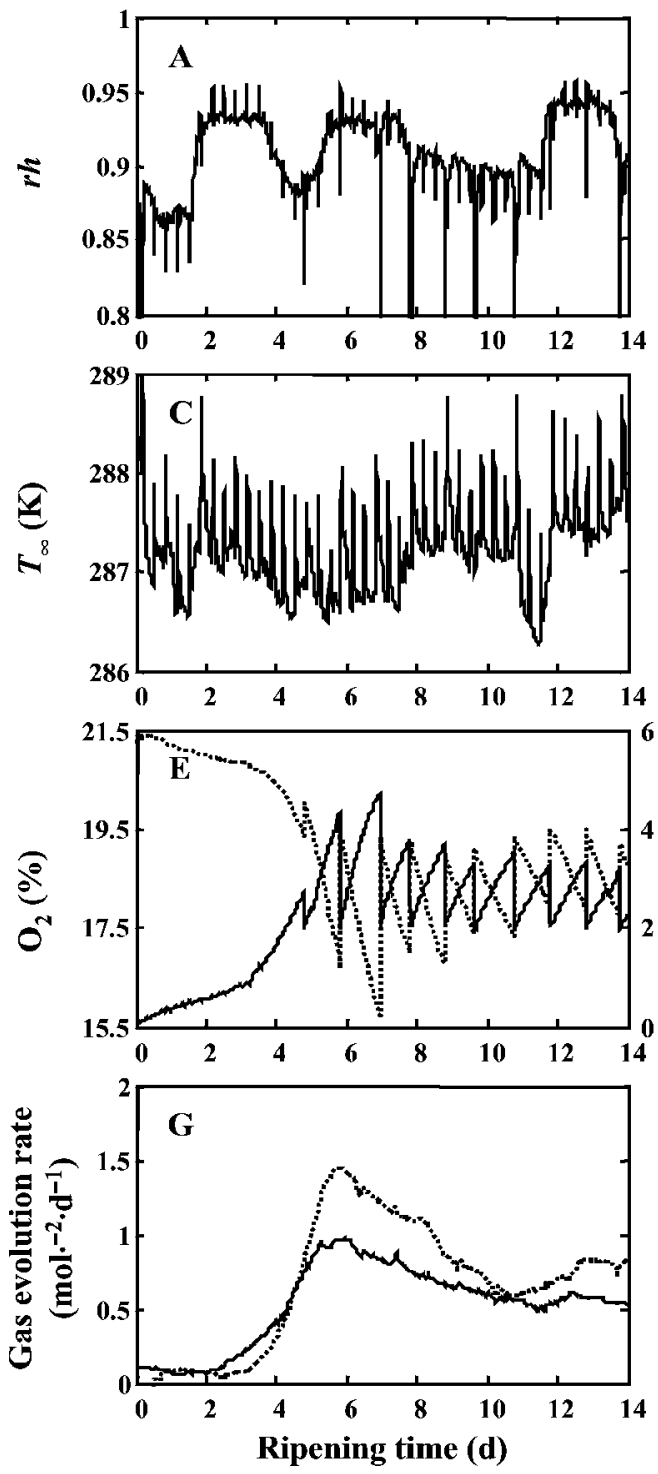

Run 2
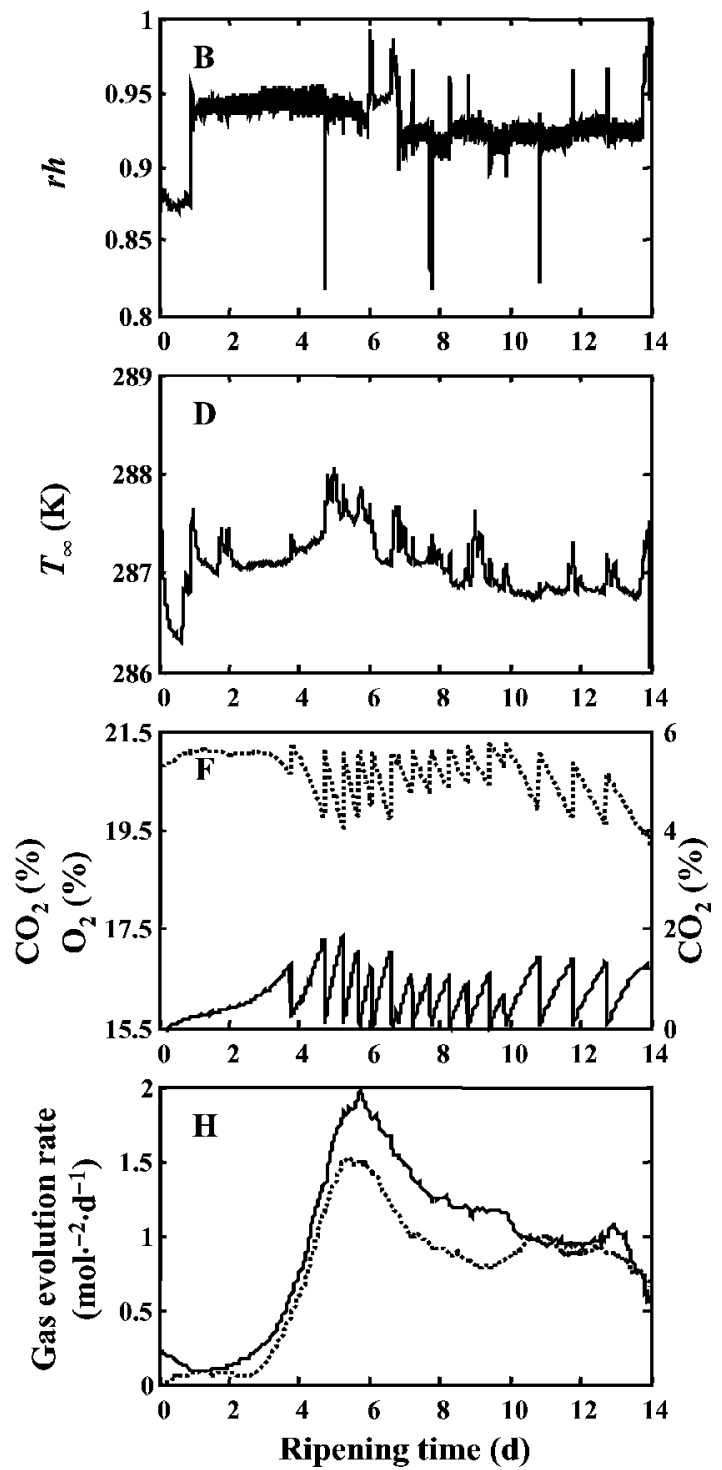

Figure 2. Data measured and calculated vs. ripening time for run 1 (panels A, C, E, G) and run 2 (panels B, D, F, G). A and B) Online measurement of ripening chamber relative humidity $(r h) ; \mathrm{C}$ and $\mathrm{D})$ online measurement of the ripening chamber temperature $\left(T_{\infty}\right)$; $\mathrm{E}$ and $\mathrm{F}$ ) online measurement of the concentrations of oxygen $\left(\mathrm{O}_{2}\right.$, dotted line) and carbon dioxide $\left(\mathrm{CO}_{2}\right.$, solid line); $\mathrm{G}$ and $\left.\mathrm{H}\right)$ calculation of the oxygen production rate (dotted line) and the carbon dioxide consumption rate (solid line). For reasons of clarity, a 1-d moving average filter to obtain noise reduction was used for the oxygen production rate and carbon dioxide consumption rate $(G, H)$.

Most of the values were between 0.969 and 0.984 , and the average, equal to 0.976 , could be used as the $a_{w}$ value. Two phases with constant $a_{w}$ were observed (d 0 to $6, a_{w}=0.973$; and $\mathrm{d} 7$ to $14, a_{w}=0.98$ ), probably because of the growth of microflora and the increase in $\mathrm{pH}$. Except on the first day, characterized by an increase in $a_{w}$ values (from 0.969 to 0.977 ), the salt diffusion effect was not observed.

Heat Transfer. The model takes into account a temperature gradient between cheese surface and ripening chamber atmosphere caused by respiratory metabolism. The temperature measurements performed on a cheese on each run verified this hypothesis (Figure 4A and $4 \mathrm{~B}$ for runs 1 and 2 , respectively). The temperature gradient varied roughly from 0 to $0.8^{\circ} \mathrm{C}$ (run 1) and 0 to $0.65^{\circ} \mathrm{C}$ (run 2). It increased with the biological activity, with a maximum between $\mathrm{d} 5$ and 6 , as observed for the gas exchanges (Figure $2 \mathrm{G}$ and $2 \mathrm{H}$ ). Clearly, convective and radiant heat transfer and respiration heat had significant effects. 


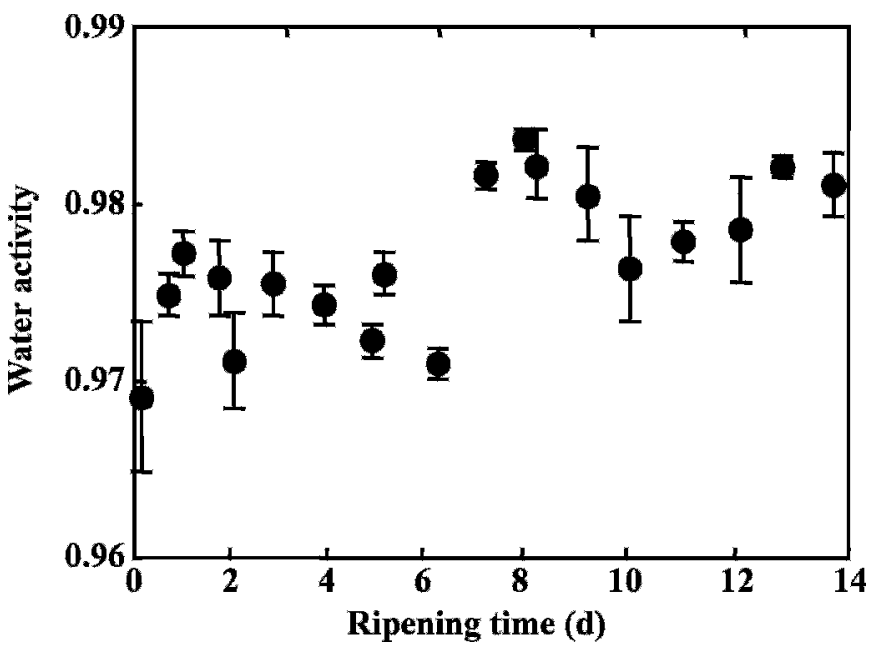

Figure 3. Changes in the water activity of the cheese surface vs. ripening time. () Mean of 4 measurements performed on 2 faces of 2 cheeses during run 1. Error bars indicate SEM.

\section{Parameter Values}

Tables 1 and 2 summarize the values of the parameters used for the mass loss estimation. The surface $a_{w}$ and the specific heat $(C)$ of the cheese were determined from experimental measurements performed during the ripening (run 1 ). The cheese emissivity values chosen were equal to those of plaster (Mirade et al., 2004). The other parameters were obtained from the literature.

The only fitting procedure to find a parameter value concerned the average convective heat transfer coefficient (Table 2). Three airflow conditions were considered: run 1, run 2 with a forced convection for the relative humidity regulation (fan on), and run 2 with a free convection (fan off). Subsets of mass experimental measurements were used for fitting this parameter: run 1: d 0 to 4; run 2 (fan on): d 1 to 3 ; and run 2 (fan off): d 7 to 9 . The convective heat transfer coefficients were used according to equation [6] to determine the average water transfer coefficients.

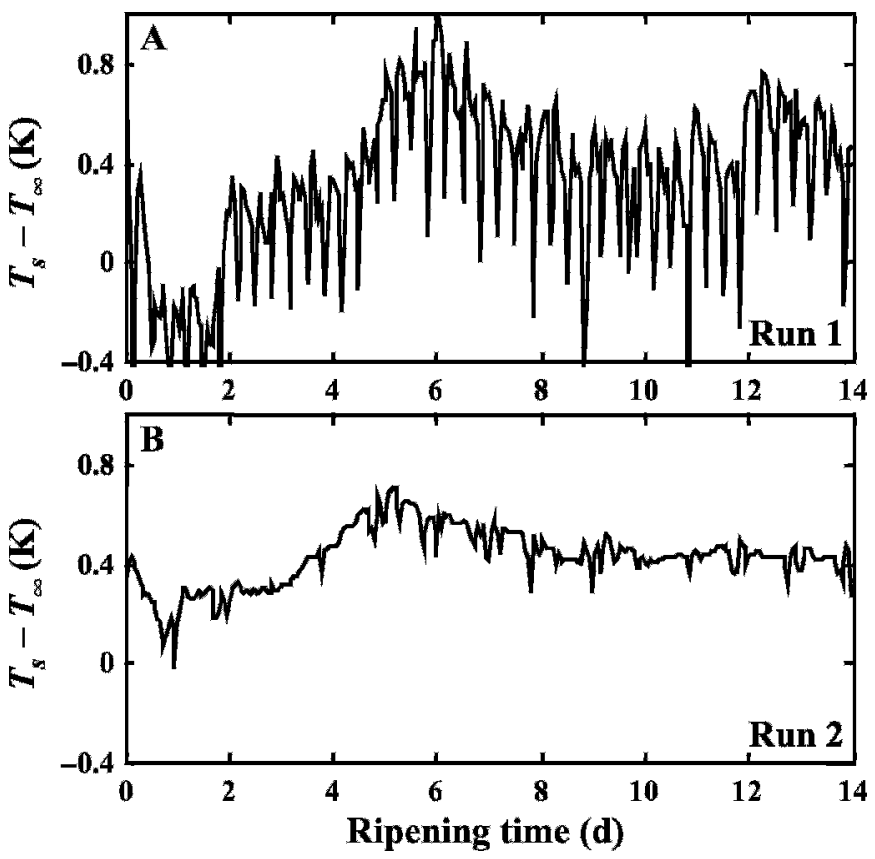

Figure 4. Difference between the recorded cheese surface temperature $\left(T_{s}\right)$ and the atmospheric temperature $\left(T_{\infty}\right)$ vs. ripening time.

\section{Mass Loss Estimation}

With an initial mass of 330 and $340 \mathrm{~g}$ for runs 1 and 2 , respectively, the mass cheese dynamics were simulated for $14 \mathrm{~d}$ in the ripening chamber. As shown on Figure 5, the model was able to represent the global evolution of the cheese mass loss. Figure 5A shows a comparison between the cheese masses measured by online weighing and as calculated by the model. The corresponding mass loss rates are shown on Figure 5B and $5 \mathrm{C}$. The cheeses lost, on average, 4.1 and $4.2 \mathrm{~g} \cdot \mathrm{d}^{-}$ ${ }^{1}$, with a total loss of 58 and $59 \mathrm{~g}$, for runs 1 and 2 , respectively. The mass loss rate was very high $(0.2$ $\mathrm{kg} \cdot \mathrm{m}^{2} \cdot \mathrm{d}^{-1}$ ) when $r h$ was $85 \%$ on $\mathrm{d} 1$ and then decreased when $r h$ increased. For example, when the relative humidity set point changed rapidly from 85 to $92 \%$ (see

Table 2. Transfer coefficient values used for mass loss estimation

\begin{tabular}{lccc}
\hline Transfer coefficient & & Salue & SE \\
\hline Average heat transfer coefficient $\left(\mathrm{W} \cdot \mathrm{m}^{-2} \cdot \mathrm{K}^{-1}\right)$ & $h$ & & \\
Run 1 (d 0-14) & & 2.51 & $1.7 \times 10^{-3}$ \\
Run 2, fan off (d 0-1 and d 7-14) & & 2.73 & $1 \times 10^{-3}$ \\
Run 2, fan on (d 1-7) & $k$ & & $3.6 \times 10^{-3}$ \\
Average water transfer coefficient $\left(\mathrm{kg} \cdot \mathrm{m}^{-2} \cdot \mathrm{Pa}^{-1} \cdot \mathrm{s}^{-1}\right)$ & & $1.80 \times 10^{-8}$ & $6.5 \times 10^{-12}$ \\
Run 1 (d 0-14) & & $1.97 \times 10^{-8}$ & $3.4 \times 10^{-12}$ \\
Run 2, fan off (d 0-1 and d 7-14) & $3.28 \times 10^{-8}$ & $14 \times 10^{-12}$ \\
Run 2, fan on (d 1-7) & & & \\
\hline
\end{tabular}

${ }^{1}$ Time frame for average heat transfer coefficient fitting: $d 0$ to 4 for run $1, d$ to 9 for run 2 (fan off), and $\mathrm{d} 1$ to 3 for run 2 (fan on). 

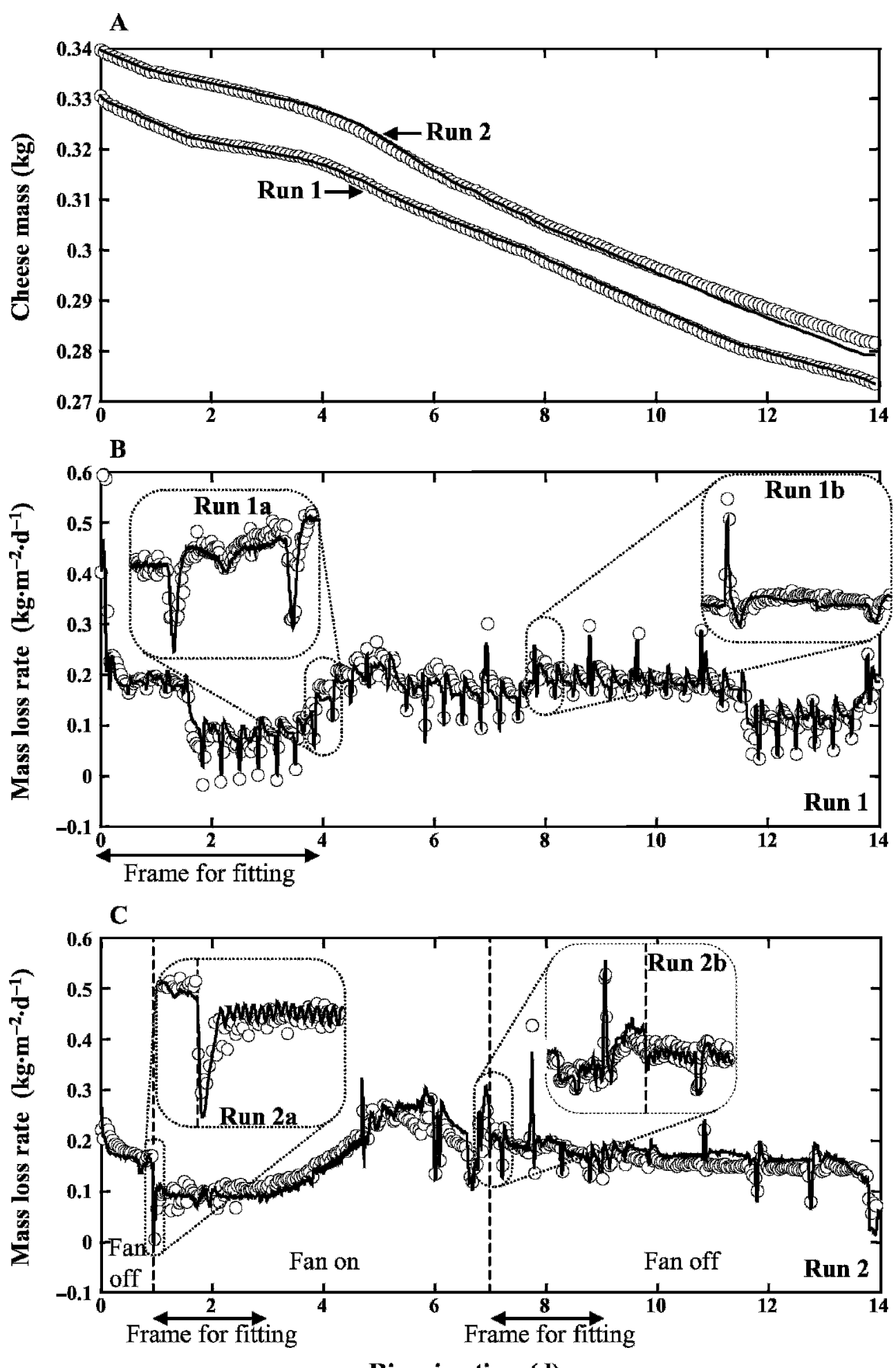

Ripening time (d)

Figure 5. A) Measured $(O)$ and estimated (solid line) cheese mass loss vs. ripening time for runs 1 and 2 . Only 2 -h mean values are represented for reasons of clarity. B and C) Measured $(O)$ and estimated (solid line) cheese mass loss rate vs. ripening time for runs 1 (B) and $2(\mathrm{C})$. Only 2 -h mean values are represented for clarity reasons except for zoom insertions, where the acquisition step is 6 min. Insertion run 1a: changes in mass loss during a defrosting event. Insertion run 1b: changes in mass loss during a dry air injection. Insertion run $2 \mathrm{a}$ : changes in mass loss during relative humidity set point and airflow velocity variations. Insertion run $2 \mathrm{~b}$ : changes in mass loss during dry air injection and airflow velocity variations. 
zoom insertion run $2 \mathrm{a}$, Figure $5 \mathrm{C}$ ), the mass loss rate decreased by at least $50 \%$.

The mass loss rate increased again with the respiratory activity to reach about $0.25 \mathrm{~kg} \cdot \mathrm{m}^{2} \cdot \mathrm{d}^{-1}$ when this activity was maximal (d 5 and 6). After this step, and to the end of the ripening process, the mass loss rate decreased in the same way as the respiratory activity decreased. This study obviously showed that the mass loss accelerations close to $\mathrm{d} 4$ were the consequence of microflora growth. For example, in run 2 the mass loss rate changed from 100 to $180 \mathrm{~g} \cdot \mathrm{m}^{-2} \cdot \mathrm{d}^{-1}$ between $\mathrm{d} 2$ and 4 , with a constant relative humidity for this time frame. In the same period, the carbon loss changed from $1.2 \mathrm{~g} \cdot \mathrm{m}^{-2} \cdot \mathrm{d}^{-1}\left(0.1 \mathrm{~mol} \cdot \mathrm{m}^{-2} \cdot \mathrm{d}^{-1}\right)$ to $9 \mathrm{~g} \cdot \mathrm{m}^{-2} \cdot \mathrm{d}^{-1}(0.75$ $\mathrm{mol} \cdot \mathrm{m}^{-2} \cdot \mathrm{d}^{-1}$; see Figure $2 \mathrm{H}$ ). As a consequence, the mass loss rate changes could not be explained only by the carbon loss changes, and the biological activities also induced water evaporation. This result showed that the biological activity had to be taken into account and was correctly represented by the model.

The residual (differences between observed and predicted values) at the end of the runs were $-0.09 \mathrm{~g}(0.17 \%$ of the total mass loss) for run 1 and $-1.7 \mathrm{~g}$ (2.9\% of the total mass loss) for run 2 . The relative errors, defined as the residual standard deviation divided by the value range, were equal to 0.65 and $1.86 \%$ for the mass and 2.13 and $3.18 \%$ for the mass loss rate for runs 1 and 2 , respectively.

Another significant property of the model was to allow a good fitting between measured and calculated mass loss values for fast changes in the working conditions. For example, fast relative humidity changes linked to a defrosting event (see Figure 5B, zoom insertion run 1a) or to dry-air injection (see Figure 5B, zoom insertion run $1 \mathrm{~b}$, and the left part of the zoom insertion run $2 \mathrm{~b}$ ) were correctly represented by the model. In fact, the general shape of the mass loss rate vs. time was in good agreement with the changes in relative humidity of the ripening chamber and in the respiratory activity of the cheese flora.

\section{CONCLUSIONS}

This study related the modeling of Camembert-type cheese mass loss during the ripening steps. A simple model was proposed for the online estimation of cheese mass loss. This model was established by taking into account 3 hypotheses: 1) Water activity was assumed to be constant; thus, water diffusion from the core to the rind of the cheese and water content at the surface level were not represented. 2) Even if temperature variations were low in the ripening chamber and temperature gradients were small between the cheese and the chamber, the major role of thermal exchange on mass transfer needed to take into account the cheese surface temperature. 3) The production of respiration heat could not be neglected in the heat balance. No substrate information was used (e.g., lactose and lactate consumptions that could be obtained only by offline sample analysis). Oxygen consumption and $\mathrm{CO}_{2}$ production rates were used directly to compute the heat balance.

The main model characteristic was a thermal balance between the atmosphere and the cheese surface, which allowed us to take into account the respiration heat and the associated evaporation. Validation with 2 experimental ripenings confirmed that no other phenomena, such as water diffusion inside the product or the temperature gradient inside the cheese, were necessary for the mass loss estimation.

\section{ACKNOWLEDGMENTS}

The authors thank T. Cattenoz, H. Guillemin, M.-N. Leclercq-Perlat, F. Lercornue, B. Perret, D. Picque, M. Savy, and C. Vermenot, who were in charge of the design and monitoring of the ripening rooms and of the cheese-ripening experiments.

\section{REFERENCES}

Blanc, B., J. O. Bosset, B. Martin, and J. Jimeno. 1983. Echanges gazeux à la surface du fromage de gruyère en cours de maturation. Schweiz. Milchw. Forsch. 12:30-34.

Chirife, J., and H. A. Iglesias. 1978. Equations for fitting water sorption isotherms of foods: Part I-A review. J. Food Technol. 13:159-174

Choisy, C., M. Desmazeaud, J. C. Gripon, G. Lamberet, and J. Lenoir. 2000 . The biochemistry of ripening. Pages $82-151$ in Cheesemaking, from Science to Quality Assurance. A. Eck and J. C. Gillis, ed. Lavoisier Publishing, Paris, France.

Desobry, S., and J. Hardy. 1994. Camembert cheese water loss through absorbent packaging. J. Food Sci. 59:986-989.

Hardy, J. 1985. Diffusion du chlorure de sodium et activité de l'eau des fromages. Sci. Aliments 5:153-162.

Hardy, J. 2000. Water activity and cheese salting. Pages $60-81$ in Cheesemaking, from Science to Quality Assurance. A. Eck and J. C. Gillis, ed. Lavoisier Publishing, Paris, France.

Hardy, J., and J. Scher. 2000. Physical and sensory properties of cheese. Pages 447-473 in Cheesemaking, from Science to Quality Assurance. A. Eck and J. C. Gillis, ed. Lavoisier Publishing, Paris, France.

Harris, M. B., J. K. Carson, J. Willix, and S. J. Lovatt. 2004. Local surface heat transfer coefficients on a model lamb carcass. J. Food Eng. 61:421-429.

Kang, J. S., and D. S. Lee. 1998. A kinetic model for transpiration of fresh produce in a controlled atmosphere. J. Food Eng. 35:65-73.

Kondjoyan, A., and J. D. Daudin. 1997. Heat and mass transfer coefficients at the surface of a pork hindquarter. J. Food Eng. 32:225-240.

Leclercq-Perlat, M. N., F. Buono, D. Lambert, E. Latrille, E. Spinnler, and G. Corrieu. 2004. Controlled production of Camembert-type cheeses. Part I: Microbiological and physicochemical evolutions. J. Dairy Res. 71:346-354.

Macedo, A. C., F. X. Malcata, and J. C. Oliviera. 1997. Effect of production factors and ripening conditions on the characteristics of Serra cheese. Int. J. Food Sci. Technol. 32:501-511.

Marquardt, D. 1963. An algorithm for least-squares estimation of nonlinear parameters. SIAM J. Appl. Math. 11:431-441. 
Mirade, P. S., T. Rougier, J. D. Daudin, D. Picque, and G. Corrieu. 2006. Effect of design of blowing duct on ventilation homogeneity around cheeses in a ripening chamber. J. Food Eng. 75:59-70.

Mirade, P. S., T. Rougier, A. Kondjoyan, J. D. Daudin, D. Picque, and G. Corrieu. 2004. Caractérisation expérimentale de l'aéraulique d'un hâloir de fromagerie et des echanges air-produit. Lait 84:483-500.

Mitchell, D., O. F. von Meien, and N. Kriegerc. 2003. Recent developments in modeling of solid-state fermentation: Heat and mass transfer in bioreactors. Biochem. Eng. J. 13:137-147.

Nagel, F. J., J. Tramper, M. Bakker, and A. Rinzema. 2001. Model for online moisture-content control during solid-state fermentation. Biotechnol. Bioeng. 72:231-243.

Ozisik, N. M. 1985. Heat Transfer: A Basic Approach. McGraw-Hill, New York, NY.

Pajonk, A. S., R. Saurel, J. Andrieu, P. Laurent, and D. Blanc. 2003. Heat transfer study and modeling during Emmental ripening. J. Food Eng. 57:249-255.

Perry, R. H., and D. W. Green. 1997. Perry's Chemical Engineers' Handbook. McGraw-Hill, New York, NY.

Picque, D., M. N. Leclercq-Perlat, and G. Corrieu. 2006. Effect of atmospheric composition on respiratory behavior, weight loss, and appearance of Camembert-type cheeses during chamber ripening. J. Dairy Sci. 89:3250-3259.

Raimbault, M. 1998. General and microbiological aspects of solid substrate fermentation. Electron. J. Biotechnol. 1(3). Online. Available: http://www.ejbiotechnology.info/content/vol1/issue3/ full/9/index.html
Ramet, J. P. 2000. Comparing ripening technology of the various types of cheese. Pages 418-446 in Cheesemaking, from Science to Quality Assurance. A. Eck and J. C. Gillis, ed. Lavoisier Publishing, Paris, France.

Riahi, M. H., I. C. Trelea, M. N. Leclercq-Perlat, D. Picque, and G. Corrieu. 2007. Model for changes in weight and dry matter during the ripening of a smear soft cheese: Effects of temperature and of relative humidity. Int. Dairy J. 17:946-953.

Rüegg, M., and B. Blanc. 1976. Effect of $\mathrm{pH}$ on water vapor sorption by caseins. J. Dairy Sci. 59:1019-1024.

Saucedo-Castañeda, G., M. Gutiérrez-Rojas, G. Bacquet, M. Raimbault, and G. Viniegra-González. 1990. Heat transfer simulation in solid substrate fermentation. Biotechnol. Bioeng. 35:802-808.

Saurel, R., A. Pajonk, and J. Andrieu. 2004. Modelling of French Emmental cheese water activity during salting and ripening periods. J. Food Eng. 63:163-170.

Simal, S., S. Sanchez, J. Bon, A. Femenia, and C. Rossello. 2001. Water and salt diffusion during cheese ripening: Effect of the external and internal resistances to mass transfer. J. Food Eng. 48:269-275.

Song, Y., N. Vorsa, and K. L. Yam. 2002. Modeling respirationtranspiration in a modified atmosphere packaging system containing blueberry. J. Food Eng. 53:103-109.

Weissenfluh, A., and Z. Puhan. 1987. The influence of the climatic conditions on the growth of Penicillium camemberti and the quality of Camembert cheese. Schweiz. Milchw. Forsch. 16:37-44.

World Meteorological Organization. 2000. General Meteorological Standards and Recommended Practices. Appendix A: Corrigendum. WMO Tech. Reg. Vol. 49. World Meteorolog. Org., Geneva, Switzerland. 